\title{
Day Times Milligram Per Milliliter Per Milligram Per Gram
}

National Cancer Institute

\section{Source}

National Cancer Institute. Day Times Milligram Per Milliliter Per Milligram Per Gram. NCI

Thesaurus. Code C117898.

Day times milligram per milliliter, divided by milligram per gram. 